\title{
Isolasi, Identifikasi Pigmen, dan Analisis Aktivitas Antioksidan Pigmen Monascus (Ascomycota)
}

\author{
DHANANG PUSPITA*, ISNAINI K. PUTRI, FITRI H. AL-JANATI, \\ MILKA M. MULYANTO \\ Teknologi Pangan, Fakultas Kedokteran dan Ilmu Kesehatan, Universitas Kristen Satya Wacana, Salatiga-Jawa Tengah
}

Diterima: 13 April 2020 - Disetujui: 1 September 2020

(C) 2020 Jurusan Biologi FMIPA Universitas Cenderawasih

\begin{abstract}
Monascus is a type of organism that can produce natural pigments. Monascus pigments have been widely used in the food and pharmaceutical industries. Besides having natural pigments, Monascus also contains antioxidants as preventing of the free radicals. The purpose of this study is to isolate, identify the type of pigment, and analyze antioxidant activity. This research method is divided into 3 stages; Monascus isolation, pigment identification with UV-vis spectrophotometer and TLC, and calculation of antioxidant activity with DPPH. The isolated Monascus had 3 pigment fractions and contained a total carotenoid of $18.55 \mu \mathrm{g} / \mathrm{g}$, total orange pigment of $278.25 \mathrm{units} / \mathrm{mL}$, and red pigment of 235.75 units/mL. Antioxidant activity of $4.22 \mathrm{ppm}$ and included in the high category.
\end{abstract}

Key words: antioxidant; monascus; pigment.

\section{PENDAHULUAN}

Karotenoid adalah pigmen berwana kuning, merah, serta orange yang secara alami terdapat pada tumbuhan dan hewan. Lebih dari 100 macam karotenoid terdapat di alam, tetapi hanya beberapa macam yang telah dapat diisolasi atau disintesa untuk bahan pewarna makanan. Karotenoid merupakan senyawa yang tidak larut dalam air dan sedikit larut dalam minyak atau lemak (Rao \& Rao, 2007). Ketersediaan $\beta$-karoten sebagai sumber vitamin A, terutama dari tanaman sering bersifat musiman. Selain itu, vitamin A yang berasal tanaman maupun hewan juga mudah mengalami kerusakan akibat pengolahan (Booth et al., 1992). Alternatif lain dalam mencari sumber vitamin $\mathrm{A}$ adalah dengan menggunakan mikroba dan jamur yang mempunyai beberapa keuntung-

* Alamat korespondensi:

Teknologi Pangan, Fakultas Kedokteran dan Ilmu Kesehatan, UKSW. J1. Kartini No.11A Salatiga-Jawa Tengah 50711. E-mail: dhanang.puspita@uksw.edu. an antara lain tidak tergantung iklim, dan dapat memanfaatkan limbah hasil pertanian sebagai substrat (Nuraida et al., 1996).

Beberapa jenis jamur yang dapat menghasilkan pigmen, seperti jamur angkak (Monascus purpureus). Monascus purpureus dari keluarga monastik dan dari kelas Ascomycota yang memiliki ciri khas mampu menghasilkan metabolit sekunder berwarna kuning, oranye atau merah (Juzlova et al., 1996). Monascus dapat dengan mudah tumbuh di beberapa ekosistem sehingga mudah untuk didapatkan. Pigmen Monascus atau angkak telah menjadi tradisi pangan di Asia timur (Dikshit \& Tallapragada, 2011; Mukherjee \& Singh, 2011). Pigmen Monascus diaplikasikan pada beberapa kelompok pangan, yaitu untuk mewarnai produk pangan hewani, minuman, pangan laut (sea food) dan nata de coco, dan pengobatan tradisional Tiongkok (Panda et al., 2010). Di Cina, Taiwan, dan Filipina angkak telah digunakan sebagai pewarna makanan maupun minuman seperti chinese cheese dan bagoong makanan khas Filipina dan anggur merah (Susanti, 1998). Dosis yang digunakan untuk 
pewarna pangan hewani berkisar 2000-4000 ppm ekstrak Monascus. Untuk minuman ringan, konsentrasi yang digunakan dapat lebih rendah, yaitu 0,002-0,005\% (2-5 ppm). Minuman anggur merah memerlukan konsentrasi yang lebih tinggi, yaitu 0,2-1,0 \% (200-1000 ppm). Untuk nata de coco, pigmen Monascus ditambahkan setelah terbentuk nata, sehingga nata dapat terwarnai (Sheu et al., 2000).

Selain memproduksi pigmen, Monascus juga menghasilkan enzim a dan $\beta$-amilase, glukoamilase, protease, dan lipase. Monascus dalam bentuk tepung dapat dijadikan campuran makanan dan minuman suplemen sebagai penurun kadar kolesterol darah. Kegunaan monascus juga dapat mengobati berbagai penyakit termasuk infeksi, gangguan pencernaan termasuk diare, dan meningkatkan sirkulasi darah. Berdasarkan resep obat-obatan Tiongkok, monascus mampu menyembuhkan penyakit asma dan kelainan urinasi (Steinkraus, 1983). Tujuan dari penelitian ini adalah untuk mendapatkan isolat murni Monascus, kemudian mengidenfikasi pigmen, dan menghitung aktivitas antioksidannya.

\section{METODE PENELITIAN}

Penelitian ini bersifat eksperimental laboratoris yang dilakukan di Laboratorium Mikrobiologi FKIK UKSW. Bahan-bahan yang digunakan dalam penelitian ini adalah media Potatto Dextrose Agar (Merck), aquades, nasi yang ditumbuhi angkak, metanol (Merck), heksana (Merck), dietil eter (Merck), dan kloroform (Merck). Alat yang digunakan pada penelitian ini ; Spektrofotometer (Genesys 10S UV-VIS), Centrifuge (Hettich Zentrifuge), Autoclaf (AllAmerican), tabung centrifuge (Corning), timbangan analitik (Ohaus \& Acis Bc-000), Vortex (Vielt scientifica), Micropipet (DLab), kuvet (Spectra cuvette), magnetic stirrer (IKA.CMAG,HS4), Mikroskop (Nikon). Adapun tahapan penelitian meliputi; isolasi Monascus, uji pertumbuhan, produksi pigmen, ekstraksi pigmen, dan analsis pigmen dengan Kromatografi lapis tipis (KLT) dan spektrofotometri, dan aktivitas antioksidan dengan DPPH (1,1-difenil-2pikrilhidrazil).

\section{Isolasi Monascus}

Sebanyak $11 \mathrm{~g}$ potatoe dextrose agar (PDA) dilarutkan dengan $250 \mathrm{~mL}$ aquadest steril kemudian dipanaskan hingga larut sempurna. Setelah itu disterilkan dengan autoklaf selama 15 menit pada suhu $121^{\circ} \mathrm{C}$ dan tekanan 2 atm, kemudian media dituang ke dalam cawan petri steril hingga memadat. Angkak yang tumbuh di nasi yang ditandai warna kuning/jingga dicuplik dengan jarum ose, kemudian digoreskan pada permukaan PDA dan selanjutnya diinkubasi dalam inkubator dengan suhu $27{ }^{\circ} \mathrm{C}$ selama 2-3 hari hingga muncul miselia dan spora berwarna kuning/jingga. Isolat kemudian dipindahkan dalam agar miring berisi PDA sebagai kultur murni.

\section{Uji Pertumbuhan}

Dicuplik spora isolat murni dari agar miring dengan menggunakan jarum ose lalu diinokulasikan pada titik tengah cawan petri yang berisi media PDA steril yang telah memadat. Setelah itu diinkubasi selama 2 - 3 hari dalam inkubator suhu $27^{\circ} \mathrm{C}$. Pengamatan dilakukan setiap 24 jam sekali dan dilakukan penghitungan panjang jari-jari pertumbuhan Monascus dihitung dari titik tengah cawa petri.

\section{Produksi Pigmen Monascus}

Ditimbang sebanyak $100 \mathrm{~g}$ beras, lalu dicuci bersih dikukus sekitar 20 menit. Setelah didinginkan dalam nampan lalu dicampurkan dengan angkak yang sudah dibiakan di medium agar miring dan diletakan di bawah matahari langsung selama 2 - 3 hari sampai mengering dan ditumbuhi miselium Monascus. Setelah beras ditumbuhi Monascus secara merata lalu dilakukan pengayakan dengan mesh ukuran 60 hingga didapat serbuk angkak.

\section{Ekstraksi Pigmen}

Serbuk angkak sebanyak $1 \mathrm{~g}$ dilarutkan dalam pelarut heksana, methanol, eter, dan kloroform 
masing-masing $9 \mathrm{~mL}$. Campuran dihomogenkan dengan menggunakan vortex sekitar 3 menit, kemudian disentrifugasi pada kecepatan 40.000 rpm selama 15 menit. Setelah itu dipisahkan supernatan dan pelet. Supernatan yang dihasilkan adalah ekstrak pigmen Monascus.

\section{Fraksi Pigmen dengan Spektrofotometer dan KLT}

Sebanyak $4 \mathrm{~mL}$ supernatan dipindai dengan spektroforometer UV-vis pada panjang gelombang 350-550 nm. Hasil pemindaian kemudian diolah dengan menggunakan perangkat lunak Origin versi 20.

\section{Fraksi Pigmen dengan Spektrofotometer dan KLT}

Sebanyak $1 \mathrm{~mL}$ supernatan dipekatkan dengan cara diuapkan dengan udara panas. Supernatan yang sudah pekat kemudian ditotolkan pada plat KLT dengan pipa kapiler. KLT kemudian dicelupkan dalam larutan yang berisi eluen (1:1:1:1); heksana, methanol, eter, dan kloroform, lalu dihitung RF-nya berdasar fraksi pigmen yang terbentuk.

\section{Analisis Total Karotenoid}

Analisis karotenoid (Rodriguez-amaya, 2001) dilakukan dengan Uji petik dilakukan dengan mengambil $1 \mathrm{ml}$ sampel kemudian dilarutkan dalam $4 \mathrm{ml}$ aseton di dalam tabung reaksi lalu divortex selama 1 menit. Setelah divortex kemudian disentrifugasi dengan kecepatan 4.000 rpm selama 5 menit. Supernatan kemudian diukur dengan menggunakan spektrofotometer UV-Vis pada panjang gelombang $450 \mathrm{~nm}$ dan sebagai blangko/kontrol digunakan minyak kelapa tanpa penambahan minyak buah merah. Penghitungan konsentrasi karotenoid disarakan rumus:

$$
\text { Total Karotenoid }(\mu \mathrm{g})=\frac{A 450 \times 4 \mathrm{ml} \times 10 x^{6}}{2.592 \times 100}
$$

\section{Analisis Determinasi Pigmen}

Ekstrak pigmen diukur dengan spektrofotometer UV-vis pada panjang 440 dan $500 \mathrm{~nm}$ untuk mendeterminasi pigmen kuning dan merah dan akan dihasilkan kandungan pigmen unit/mL. Penghitungan didasarkan persamaan (Hailing-Tan et al., 2018; Kaur et al., 2008):

(jingga) Satuan nilai warna $/ \mathrm{mL}=\mathrm{ab} 440 \times$ faktor pengenceran $\times 100 /$ volume sampel

(Merah) Satuan nilai warna $/ \mathrm{mL}=\mathrm{ab} 500 \times$ faktor pengenceran $\times 100 /$ volume sampel

\section{Analisis Antioksidan DPPH}

Analisis antioksidan dilakukan dengan disiapkan larutan stok DPPH 50 ppm dengan melarutkan $5 \mathrm{mg}$ DPPH ke dalam $100 \mathrm{ml}$ etanol PA. Disiapkan juga larutan kontrol yang berisi 2 $\mathrm{ml}$ etanol PA dan $1 \mathrm{ml}$ larutan stok DPPH 50 ppm. Uji petik dilakukan dengan mengambil $1 \mathrm{ml}$ sampel kemudian dilarutkan dalam $4 \mathrm{ml}$ aseton di dalam tabung reaksi lalu divortex selama 1 menit. Setelah divortex kemudian disentrifugasi dengan kecepatan $4.000 \mathrm{rpm}$ selama 5 menit. Supernatan diambil $1 \mathrm{ml}$ dan dicampur dengan larutan stok DPPH 50 ppm sebanyak $3 \mathrm{ml}$ kemudian didiamkan selama 30 menit setelah itu diukur dengan spektrofotometer pada panjang gelombang $517 \mathrm{~nm}$. Data yang diperoleh adalah \% Effective Scavenging dan konsentrasi senyawa uji kemudian diolah menggunakan analisis regresi linier untuk mendapatkan konsentrasi penangkapan Aktivitas penangkapan radikal bebas 50\% (IC50) (Himamura et al., 2014).

\section{HASIL DAN PEMBAHASAN}

Hasil isolasi Monascus menunjukkan bahwa miselium Monascus yang berbentuk bulat (Gambar 1). Miselium yang tumbuh memenuhi cawan petri, serta hifanya berwarna putih. Hasil produksi ditunjukkan pada gambar $1 \mathrm{~b}$, yakni serbuk spora dari beras yang telah ditumbuhi oleh Monascus.

Hasil uji pertumbuhan (Tabel 1) menunjukkan bahwa, pada hari pertama rerata panjang jari-jari pertumbuhan sekitar $1,72 \mathrm{~cm}$. Pada hari ke-2 rerata pertumbuhan mencapai 3,36 dan pada hari ke-4 semua seragam pertumbuhannya mencapai $4,5 \mathrm{~cm}$. 


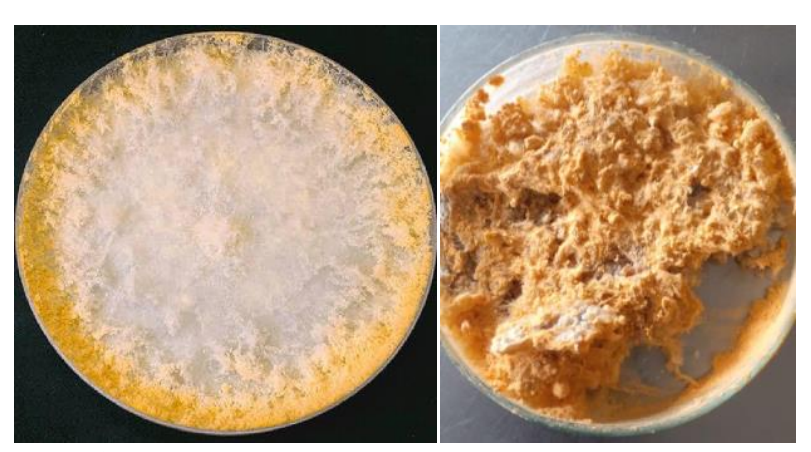

Gambar 1. Isolat Monascus dan serbuk angkak.

Tabel 1. Pertumbuhan miselium Monascus.

\begin{tabular}{ccccc}
\hline \multirow{2}{*}{ Sampel } & \multicolumn{4}{c}{$\begin{array}{c}\text { Panjang Pertumbuhan }(\mathrm{cm}) \\
\text { hari ke- }\end{array}$} \\
\cline { 2 - 5 } & 0 & 1 & 2 & 3 \\
\hline 1 & 0 & 1,5 & 2,6 & 4,5 \\
2 & 0 & 1,3 & 3 & 4,5 \\
3 & 0 & 2,1 & 3,6 & 4,5 \\
4 & 0 & 1,3 & 1,5 & 4,5 \\
5 & 0 & 1,6 & 2,1 & 4,5 \\
6 & 0 & 1,8 & 3,8 & 4,5 \\
7 & 0 & 1,8 & 3,5 & 4,5 \\
8 & 0 & 1,8 & 4,5 & 4,5 \\
9 & 0 & 2,2 & 4,5 & 4,5 \\
10 & 0 & 1,8 & 4,5 & 4,5 \\
\hline Rerata & 0 & 1,72 & 3,36 & 4,5 \\
\hline
\end{tabular}

Tabel 2. Hasil analisis total karotenoid.

\begin{tabular}{lrr}
\hline \multicolumn{1}{c}{ Pelarut } & OD $450 \mathrm{~nm}$ & $\begin{array}{c}\text { Total Karotenoid } \\
\text { ug/mg }\end{array}$ \\
\hline Heksana & 38 & 0,59 \\
Metanol & 1202 & 18,55 \\
Dietel eter & 276 & 4,26 \\
Kloroform & 433 & 6,68 \\
\hline
\end{tabular}

Hasil analisis pigmen menunjukkan bahwa adanya tingkat kelarutan pigmen yang dilarutkan dengan menggunakan pelarut A (heksana), B (metanol), C (dietil eter), dan D (kloroform) (Gambar 2). Masing-masing pelarut menunjukkan hasil yang berbeda tingkat kelarutannya terlihat dari warna yang berbeda yang dipertegas dari hasil pola spektra yang ditunjukkan pada gambar 2b. Pada gambar 2b, pelarut metanol memiliki pola spektra dengan puncak serapan tertinggi, dibandingkan dengan 3 pelarut lainnya. Masingmasing pelarut memiliki pola spektra dengan 3 puncak serapan yang menandakan ada 3 pigmen berbeda. Tiga puncak serapan juga dipertegas pada gambar 2c yaitu fraksi pigmen dengan menggunakan KLT terdapat dapat 3 fraksi pigmen. Fraksi pigmen dengan menggunakan KLT didasarkan pada berat molekul pada masingmasing ditandai dengan RF yang berbeda.

Hasil analisis karotenoid menunjukkan bahwat total karotenoid mengalami perbedaan pada masing-masing jenis pelat (Tabel 2). Total karotenoid tertinggi diperoleh dengan menggunakan pelarut metanol, dikarenakan tingkat kelarutan pigmen yang tertinggi (Gambar 2b).

Karotenoid adalah pigmen yang memiliki sifat sebagai antioksidan. Aktivitas antioksidan pada Monascus ditunjukkan dalam tabel 4 didasarkan kurva standar (Gambar 3). Aktivitas antioksidan pigmen Monascus sebesar 4,22 ppm dikategorikan tinggi karena dibawah 50 ppm.

Monascus dapat dengan mudah ditemukan karena memiliki persebaran yang luas. Secara tradisional Monascus dapat peroleh secara alami dengan menggunakan media serealia. Monascus dapat dengan mudah tumbuh di beras merah, beras putih, dan beras ketan yang sudah banyak digunakan dalam pengobatan tradisional di Tiongkok (Panda et al., 2010). Pada penelitian ini digunakan nasi yang dibiarkan di udara terbuka selama 1 - 5 hari agar ditumbuhi Monascus atau jamur angkak secara alami. Kehadiran Monascus ditandai adanya warna kuning atau merah muda yang lama kelamaan akan menebal di permukaan nasi.

Untuk mendapatkan isolat murni Monascus, maka jamur angkak pada nasi tersebut dicuplik dengan menggunakan jamur ose lalu digoreskan pada medium PDA yang khusus untuk pertumbuhan jamur. Pada medium PDA, jamur angkak akan tumbuh pada hari ke 2 dan semakin melebar pertumbuhannya pada hari ke 4. Awal pertumbuhan akan diawali dengan semakin 
banyak dan melebarnya miselium yang berwarna putih. Miselium nantinya akan keluar hifa yang pada akhirnya muncul spora dan warna jamur angkak akan berubah kekuningan lalu menjadi jingga (Gambar 1a).

Pertumbuhan jamur angkak akan mulai terlihat pada hari kedua hingga puncaknya hari ke 5 (Gambar 1a; Tabel 1). Setelah 24 jam masa inkubasi miselium yang berwarna putih lalu akan berubah menjadi kuning muda dan jingga. Untuk memanen pigmen angkak, biasanya dilakukan pada hari ke-5 saat pertumbuhan maksimal. Serbuk angkak (substrat padat) yang berasal dari spora Monascus adalah produk berupa pigmen yang dapat digunakan secara langsung (Timotius, 2004). Pigmen dari Monascus dapat dipanen dengan cara pengayakan dan hasilnya seperti ditunjukkan pada gambar 1b. Pigmen angkak dapat disimpan dalam jangka waktu yang lama dalam wadah yang kering, tertutup rapat, dan terhindar dari paparan cahaya dan panas.

\section{Analisis Pigmen Monascus}

Warna jingga pada angkak adalah pigmen alami dari karotenoid. Karotenoid memiliki banyak jenis dan tergantung sumbernya. Dari hasil analisis dengan menggunakan spektrofotometer (Gambar 2b) dan fraksi dengan menggunakan KLT (Gambar 2c) terdapat pola yang sama yakni ada 3 jenis pigmen yang berbeda. Dengan menggunakan spektrofotometer terdeteksi 3 puncak serapan, Timotius (2004) mengatakan puncak serapan terjadi pada gelombang 370, 420, dan $500 \mathrm{~nm}$ untuk masingmasing untuk pigmen kuning, oranye, dan merah. Dengan KLT, teridentifikasi 3 jenis pigmen yang terpisah.

Timotius (2004), mengatakan pigmen Monascus dibedakan menjadi dua, yaitu pigmen intraseluler (tidak larut air), dan pigmen ekstraseluler (larut air). Tingkat kelarutan pigmen ditunjukkan pada gambar 1a, dimana tingkat kelarutan tertinggi adalah pada pelarut metanol, karena sifatnya yang

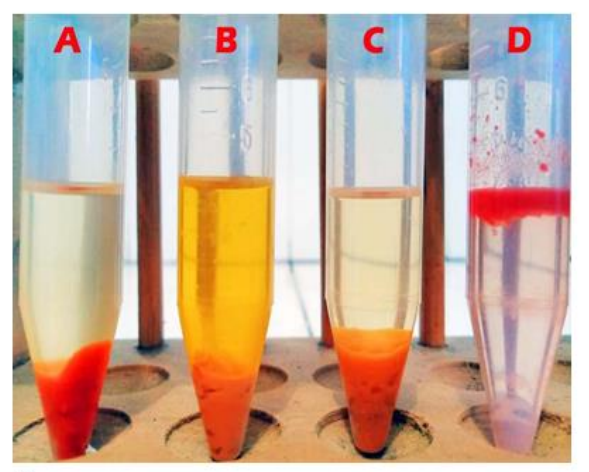

a

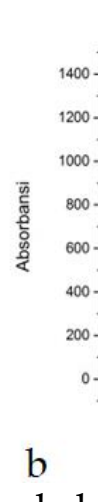

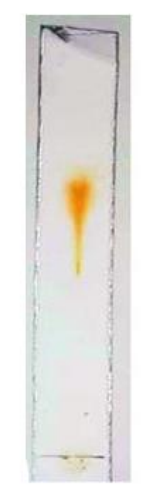

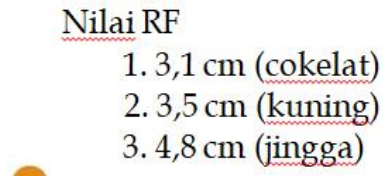

Gambar 2. Hasil ekstraksi pigmen angkak (a), pola spektra (b), dan KLT (c).

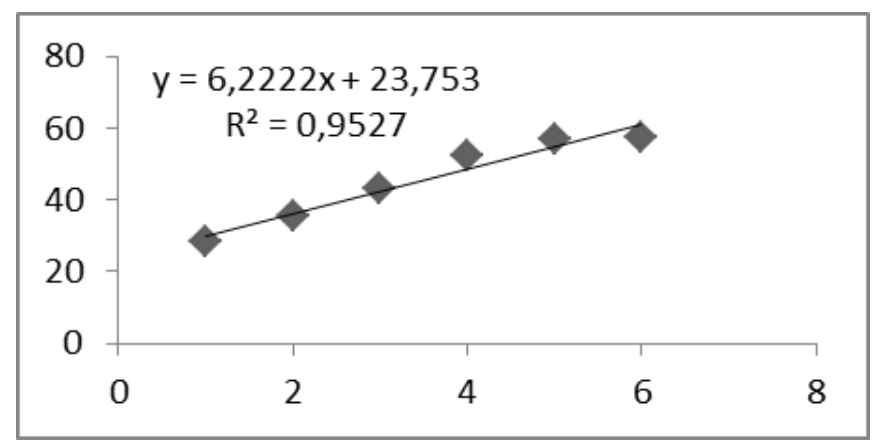

Gambar 3. Kurva standar untuk uji antioksidan pigmen Monascus. 
Tabel 3. Total unit pigmen Monascus.

\begin{tabular}{|c|c|c|c|c|}
\hline Pelarut & OD $440 \mathrm{~nm}$ & OD $500 \mathrm{~nm}$ & Jingga & Merah \\
\hline Heksan & 34 & 26 & 8,5 & 6,5 \\
\hline Metanol & 1113 & 943 & 278,25 & 235,75 \\
\hline dietieter & 265 & 251 & 66,25 & 62,75 \\
\hline Kloroform & 227 & 257 & 56,75 & 64,25 \\
\hline
\end{tabular}

Tabel 4. Aktivitas antioksidan pigmen Monascus.

\begin{tabular}{ccccccc}
\hline Konsentrasi & OD Sampel & $\begin{array}{c}\text { OD } \\
\text { Blangko }\end{array}$ & $\% \mathrm{IC}$ & Regresi Linear & yIC50 & $\begin{array}{c}\text { IC 50 } \\
(\mathrm{ppm})\end{array}$ \\
\hline $1 \times 10^{1}$ & 0,484 & & 28,29 & $\mathrm{y}=6,2222 \mathrm{x}+23,753$ & & \\
$1 \times 10^{2}$ & 0,435 & & 35,55 & $\mathrm{R}^{2}=0,9527$ & & \\
$2 \times 10^{3}$ & 0,384 & & & & \\
$3 \times 10^{4}$ & 0,323 & 0,675 & 43,11 & & \\
$4 \times 10^{5}$ & 0,292 & & 52,13 & & \\
$5 \times 10^{6}$ & 0,288 & & 56,74 & & \\
\hline
\end{tabular}

semi polar (dapat melarutkan semua jenis pigmen). Pelarut heksan, dieti eter, dan kloroform bersifat non polar dan hanya dapat melarutkan pigmen yang tidak larut air. Heksan sangat baik untuk melarutkan pigmen kuning, metanol dapat digunakan untuk melarutkan pigmen kuning dan jingga, sedangkan dietil eter dan klorofrom untuk pigmen kuning dan merah.

Tiga jenis pigmen yang terfraksi dengan menggunakan KLT kemungkinan adalah rubropuktatin dan monaskurubrin (pigmen jingga), ankaflavin dan monascin (pigmen kuning) rubropuktamin dan monaskorubramin (pigmen coklat) (Timotius, 2004). Menurut Hasim et al (2018), angkak mengandung turunan karotenoid berupa rubropunktatin, monaskorubin, dan ankaflavin. Silbir \& Goksungur (2019), mengatakan ada 3 jenis pigmen dalam Monascus yakni pigmen merah (rubropunctamin dan monascurubramin), pigmen jingga (rubro-punctatin dan monascurubramin), dan pigmen kuning (monascin dan ankaflavin). Srianta et al. (2017) mengatakan terdapat 12 jenis pigmen pada Monascus yakni; rubropunctatin, monascorubrin, rubropunctamine, monasco-rubramine, monascin, ankaflavin, xanthomonascin A, xanthomonascin B, monascopyridine A, monascopyridine B, yellow II and monapilol $\mathrm{B}$, namun dalam penelitiannya hanya menemukan 2 yakni; monapilol B dan rubropunctamine. Perbedaan jenis pigmen tersebut dipengaruhi oleh spesies Monascus, jenis substrat, sumber nitrogen, $\mathrm{pH}$, suhu, dan pengadukan.

Pigmen kuning, jingga, dan merah adalah representasi dari karotenoid. Karotenoid total adalam pigmen Monascus berbeda-beda konsentrasinya, tergantung dari pelarut yang digunakan. Dengan pelarut metanol konsentrasi total karotenoid adalah yang tebesar yakni 18,55 $\mu \mathrm{g} / \mathrm{g}$, sedangkan total pigmen jingga sebesar 278,25 unit/mL dan pigmen merah sebesar 235,75 unit/mL. Pada pelarut heksan, dietil eter, dan kloroform relatif sedikit.

\section{Antioksidan Pigmen Monascus}

Kandungan karotenoid atau pigmen yang ada di dalam Monascus juga dapat berperan sebagai antioksidan dan tidak bersifat toksit (Kaur et al., 2008). Antioksidan di dalam pigmen Monascus memiliki aktifitas yang tinggi karena berada di bawah 50 ppm, yakni sebesar 4,22 ppm. Penelitian Hailing-Tan (2018) juga mengatakan aktifitas antioksidan pada Monascus yang ditumbuhkan pada beras sebesar $3.59 \pm 0.14$ ppm. Perbedaan aktivitas antioksidan dipengaruhi oleh substran 
dan warna dari pigmen yang dihasilkan (Wanti et al., 2015).

Adanya kandungan antioksidan yang tinggi, pigmen Monascus banyak digunakan sebagai bahan obat-obatan tradisional untuk mengobati berbagai penyakit. Selain itu pigmen Monascus juga digunakan sebagai antikanker dan mencegah penyakit kardiovaskuler dengan memanfaatkan senyawa antioksidan di dalamnya (Pengnoi et al., 2017).

\section{KESIMPULAN}

Hasil penelitin ini dapat disimpulkan bahwa Monascus dapat diisolasi dari nasi sisa yang dibiarkan di lingkungan terbuka. Terdapat 3 fraksi pigmen yang dihasilkan dari isolat Monascus. Monascus mengandung total karotenoid 18,55 $\mu \mathrm{g} / \mathrm{g}$, total pigmen jingga 278,25 unit/mL dan pigmen merah 235,75 unit/mL. Aktivitas antioksidan pada pigmen Monascus sebesar sebesar 4,22 ppm dan masuk dalam kategori tinggi.

\section{DAFTAR PUSTAKA}

Dikshit, R., and P. Tallapragada. 2011. Monascus purpureus: A potential source for natural pigment production. Journal of Microbiology and Biotechnology Research. 1(4): 164-174.

Booth, S.L., T. Johns and H.V. Kuhnlein. 1992. Natural food sources of vitamin A and provitamin A. Food Nutr. Bull. 14: 6-19.

Hailing-Tan, X., Z. Chen, G . Tian, and X.Z. Wu. 2018. Evaluating antitumor and antioxidant activities of yellow Monascus pigments from Monascus ruber fermentation. Molecules. 23(3242): 1-12. doi:10.3390/ molecules23123242.

Hasim, Q. Hasanah, D. Andrianto, dan D.N. Faridah. 2018. Aktivitas antioksidan dan antihiperkolesterolmia in vitro dari campuran ekstrak angkak dan bekatul. Jurnal Teknologi dan Industri Pangan. 29(2): 145-154.

Himamura, T.S., Y.S. Umikura, T.Y. Amazaki, A.T. Ada, T.K. Ashiwagi, H.I. Shikawa, and H.U. Keda. 2014. Applicability of the DPPH assay for evaluating the antioxidant capacity of food additives-Inter-laboratory evaluation study. Analytical Sciences. 30: 717-721.

Juzlova, P., L. Martinkova, and V.K. Yen. 1996. Secondary metabolites of the fungus Monascus: A review. J. Ind. Microbiol. 16: 163-170.

Kaur, B., D. Chakrabortya, and H. Kaur. 2008. Production and evaluation of physicochemical properties of red pigment from Monascus purpureus MTCC 410. The Internet Journal of Microbiology. 7(1): 1-6.

Mukherjee, G., and S.K. Singh. 2011. Purification and characterization of a new red pigment from Monascus purpureus in submerged fermentation. Process Biochemistry. 46: 188-192.

Nuraida, L., S.H. Sihombing, dan S. Fardiaz. 1996. Produksi karotenoid pada limbah cair tahu, air kelapa dan onggok oleh kapang Neurospora sp. Buletin Teknologi dan Industri Pangan. 1: 67-74.

Panda, B.O., S. Javed, and M. Ali. 2010. Production of angkak through co-culture of Monascus Purpureus and Monascus Ruber. Brazilian Journal of Microbiology. 41: 757-764.

Pengnoi, P.M., R. Mahawan, C. Khanongnuch, and S. Lumyong. 2017. Antioxidant properties and production of monacolin $\mathrm{K}$, citrinin, and red pigments during solid state fermentation of purple rice (Oryzae sativa) varieties by Monascus purpureus. Czech J. Food Sci. 35(1): 32-39.

Rao, A.V., and L.G. Rao. 2007. Carotenoid and human health. Pharmacological Research. 55: 207-216.

Rodriguez-amaya, D.B. 2001. A Guide to Analysis In Food. Washington: ILSI PRESS.

Sheu, F., C.L. Wang, and Y.T. Shyu. 2000. Fermentation of Monascus purpureus on bacterial cellulose-nata and the color stability of Monascus-nata complex. J. Food Science. 65(2): 342-345.

Silbir, S., and Y. Goksungur. 2019. Natural red pigment production by Monascus Purpureus in submerged fermentation systems using a food industry waste: Brewer's spent grain. Foods. 8(161): 2-14.

Srianta, I., E. Zubaidah, T. Estiasih, Y. Iuchi, Harijono, and M. Yamada. 2017. Antioxidant activity of pigments derived from Monascus purpureus fermented rice, corn, and sorghum. International Food Research Journal. 24(3): 11861191.

Steinkraus, H. 1983. Indigenous fermented food. Marcel. New York.

Susanti, M.T. 1998. Optimasi kondisi operasi proses produksi pigmen angkak pada fermentasi beras oleh Monascus purpureus. Semarang: Universitas Diponegoro - Press.

Timotius, K.H. 2004. Produksi angkak oleh Monascus. Jurnal Teknol. dan Industri Pangan. 15(1): 79-86.

Wanti, S., M.A.M. Andriani, dan N.H.R. Parnanto. 2015. Pengaruh berbagai jenis beras terhadap aktivitas antioksidan pada angkak oleh Monascus purpureus. Biofarmasi. 13(1): 1-5. 